\title{
Extending the Explanatory Scope of Evolutionary Theory: The Origination of Historical Kinds in Biology and Culture
}

\author{
Günter P. Wagner* and Gary Tomlinson ${ }^{\dagger}$
}

\begin{abstract}
Two welcome extensions of evolutionary thinking have come to prominence over the last thirty years: the so-called "extended evolutionary synthesis" (EES) and debate about biological kinds and individuals. These two agendas have, however, remained orthogonal to one another. The EES has mostly restricted itself to widening the explanations of adaptation offered by the preceding "modern evolutionary synthesis" by including additional mechanisms of inheritance and variation; while discussion of biological kinds has turned toward philosophical questions of essential vs. contingent properties of life forms and realist vs. epistemological approaches to categorization and classification. Here we attempt to broaden the explanatory scope of evolutionary theory by linking these two agendas. We expand on the mechanistic orientation of the EES, using new understandings of networked systems of components in order to engage the distinct intellectual challenge of the origination of historical kinds. With this phrase we designate a subset of natural kinds that acquires, through evolutionary processes, a quasi-independent lineage-history. Such kinds emerge in both biology and culture, and we enlarge the limited number of historical kinds that have thus far been recognized in evolutionary biology in a series of paradigmatic exemplars, from genes and cell types to rituals and music. For each exemplar we discern specific mechanisms by which it arose and persists; comparing these, we suggest a general unity in the ways in which diverse historical kinds originate.
\end{abstract}

$$
\begin{gathered}
\text { Keywords } \\
\text { natural kinds } \bullet \text { historical kinds } \bullet \text { cultural kinds } \bullet \text { individuals } \bullet \text { evolutionary theory } \\
\text { extended evolutionary theory } \bullet \text { homology }
\end{gathered}
$$

*Department of Ecology and Evolutionary Biology, Yale Systems Biology Institute, Yale University, New Haven, CT 06520, USA (D) https://orcid.org/0000-0002-3097-002X

$\dagger$ Department of Music, Whitney Humanities Center, Yale University, New Haven, CT 06520, USA

Received 10 December 2019; Revised 29 June 2020; Accepted 8 September 2020 doi:10.3998/ptpbio.2095 


\section{Introduction to Historical Kinds}

For the last several decades, a set of concerns has exerted increasing pressure on the modern evolutionary synthesis (MES) of the mid-twentieth century, with the goal of broadening the explanatory powers of evolutionary theory. A much-discussed version of this expanded view, the "extended evolutionary synthesis" (EES), builds on but does not repudiate the earlier formation (Pigliucci 2007; Pigliucci and Müller 2010; Laland, Uller, et al. 2015, http: //extendedevolutionarysynthesis.com). While proponents of the MES maintain that natural selection, modeled as chance genetic variants differentially transmitted, offers an adequate explanatory model for adaptation, EES advocates aim to track also more circuitous pathways, including especially developmental bias canalizing certain evolutionary trends, phenotypic plasticity shaping the evolvability of organisms, and niche construction, through which organisms alter their own fitness landscapes and those of the organisms around them.

Despite these novel agendas, the EES follows the MES closely in one major respect: in each case the aim is to explain adaptations, that is, the fit of organisms to their environments. This shared aim reflects a shared limitation, since one of the main intellectual achievements of the MES was the recognition that the evolution of adaptations and the origin of species are distinct phenomena, requiring different explanatory models (Gould 1982). The architects of the MES realized that the origination of distinct lineages, as represented in the central, Darwinian instance of speciation, can result from a number of different causes, including the chance accumulation of genetic incompatibilities in geographically isolated populations, hybridization, polyploidization, and others. They understood the implication of this: that natural selection, the main explanation for adaptation, can be part of the process of speciation, but it is neither necessary nor sufficient for it. In this, the MES overcame a major flaw in the Darwinian heritage. It was because of the conflation of adaptation and speciation that the foundational document of evolutionary thought, The Origin of Species, could not deliver what its title promised to explain. The adaptedness of organisms and their clustering in distinct lineages of descent require, in short, different explanations.

This notion of clustering introduces a broader problem that has preoccupied much philosophy of biology over the last thirty years: the nature and origination of biological kinds. Because of their shared adaptationist orientation, neither the MES nor the EES has been positioned to engage directly this question. We think, however, that the expanded view of mechanism proposed by the EES is a step in the right direction, one that might point toward a juncture between the EES and the discourse on biological kinds. Across a series of exemplars described in section 2, we will develop an expanded conception of evolutionary mechanisms in order to understand the origination of kinds in both biology and culture, one of the epochal outgrowths of evolution.

To set the stage for our exemplars, we need to situate ourselves briefly in the recent discourse on kinds. Our position is, first of all, an anti-essentialist one. We understand our biological and cultural kinds as reflective not of fixed essences but of processes. This processualism puts us in the camp of theorists who have turned away from metaphysical considerations of kinds (Dupré 2012; Dupré and Nicholson 2018; Griesemer 2018; Love 2018), instead understanding biological kinds to arise from networked relations among distinct entities and forces. For us, these networks, when highly organized and in stable, causal interactions, define mechanisms; and so, though mechanism is sometimes opposed to processualism and allied with metaphysical reductionism (Dupré 2017), we advocate a different possibility. The mechanisms we elaborate are not the self-enclosed entities of the reductionists, independent from the environments in which they function. They are instead relatively stable patterns of operation and function within

๑ OPEN ACCESS - PTPBIO.ORG 
the ongoing flows of biological and cultural histories. Mechanisms, for us, can never function in a vacuum, but always entail a broader context and environment by which their operation is shaped and in which their effects are felt. This much follows from a basic view of life forms as ordered but open thermodynamic systems (Bertalanffy 1969; Kauffman 1993). From this processual vantage we can see that mechanisms only ever attain a quasi-independent autonomy from their surroundings - but, by the same token, that this quasi-independence is basic to their stability, function, and identity.

All processes change through time, and so do the operations of the networked relations that arise within them (Pemberton 2018). So also, then, do the biological and cultural kinds we perceive to originate in the causal functioning of these relations. These kinds are not, in other words, eternal and unchanging, but shift with the passage of time, changing, slowly or rapidly, both their mechanistic networks and the processes around them. They are, in a word, bistorical through and through. Historical kinds have been recognized and theorized for several decades now in biological theory. This theorization was stimulated in part as a response to the doubts of some neo-positivist philosophers that life sciences could have the same nomological or law-abiding status as physics and chemistry (Griffiths 1999; Millikan 1999; Dupré 2017; Millikan 2017). It was stimulated also, more consequentially in our view, by the central role that the evolution and change of life forms has played in biology at least since Darwin. Darwin's fundamental achievement, after all, was the discerning of a process by which life forms could be putatively historicized. The great confirmation of his insight over the last 150 years has involved empirical verification of this historicization from many quarters.

If, however, historical kinds change across time, then they pose a basic question: how can a flexible and changing kind maintain its identity? For us the question of the self-maintenance of kinds in both biology and culture depends once again on mechanisms and their operation and function. Our historical kinds are characterized by the networks central to them of components linked in mutual, reciprocal causal effect and interdependency. These operate at scales ranging from the molecular to the societal, and from their stable operation arise the kinds they define.

Our view of "historiogenic" mechanisms, then, is similar to that advanced by Richard Boyd in support of his "homeostatic property cluster" (HPC) view of biological kinds-for us, one of the foremost interventions in the debates over biological kinds (Griffiths 1999; Boyd 1999; Brigandt 2009). In Boyd's view, biological kinds are defined by clusters of properties (or traits or features) in groups or populations. The clusters are maintained in correlated relation to one another-that is, they form mechanisms operating at many levels. The correlations are both causal, bringing about reliable changes in their effects, and contingent, in that they arise through historical processes and can change over time. The homeostasis of related clusters of properties, in other words, shows a relative but not absolute stability. Because of this, HPC kinds are definable loosely but not analytically, admitting of some members without all the properties of others and of marginal cases at the borders of the kind. This looseness of definition allows for the fact that the perceived naturalness of an HPC kind may be sacrificed by reduction of its property cluster only to those properties possessed by all of some core group. As this suggests, HPCs have an epistemological aspect to their definition. That is, they depend not only on a realist approach to the world but also in some measure on the differing research projects and orientations that bring different property clusters into focus.

The kinds we discern below may be thought of as HPC kinds, and we aim to describe and specify, in several biological and cultural arenas, the homeostatic mechanisms that are at work in defining them. This specification has the advantage of both distinguishing our kinds and assimilating them to one another. That is, it enables us to identify the special processes from 
which each arises and at the same time points toward deep commonalities among the general features of the mechanisms that function to maintain them.

We speak here of "individual" kinds and of the "individuation" of kinds, but we do not mean by this to enter into the extensive discussion of biological individuals-into, so to speak, the technical use of the word "individual." This discussion has been mainly an ontological one stimulated by the question of the units that can undergo natural selection (Gilbert, Sapp, et al. 2012; Godfrey-Smith 2014; Bueno, Chen, et al. 2018). We use the term individuation instead to name the process by which coalescing networks of interactions, as they attain a degree of stability and self-maintenance, can give rise to distinct, persisting kinds. Most or all of these mechanisms are evolved, depending in part on selection, but their stability brings about other effects, clusterings, and clumpings in the biosphere and in culture, and these are not directly attributable to selection. Our kinds are not reducible, then, to the operation of selection per se, but are emergent from systems of entities - the components making up networked mechanisms.

The processes that establish novel, individuated lineages of descent are subserved by these mechanisms that enable quasi-independent change within a kind. Here we adduce a conceptual distinction that, to our knowledge, was first fully understood in the context of species evolution and origination, namely the distinction between so-called "anagenetic" evolution, modifications that occur along a lineage of descent, and "cladogenetic" evolution, which leads to new lineages (Dupré and Nicholson 2018, 31). Similarly, for all sorts of historical kinds we must distinguish two modes of change, the modification of a kind during its history, and the origination of novel kinds. These two modes of evolutionary/historical change require different research approaches answering different sets of questions. In the case of the evolutionary modification of a historical kind we ask what drives evolutionary/historical change, what determines the direction of change, how the variation and variety that feeds historical change is generated, and how all this takes place under the governance of mechanisms of self-maintenance. In the case of the origination of historical kinds, instead, we ask how a new historical kind acquires its independence - that is, how it individuates from other such kinds-and, once its dynamics coalesces, what mechanisms maintain its coherence and autonomy over historical and evolutionary time.

This latter process of origination needs to be conceived in ways related to but reaching beyond such well-trodden areas as speciation and gene duplication. Elaborating it can help us to organize research into the origin and evolution of cell types, morphological characters, functional processes, behaviors, and patterns of cultural variation and innovation. Even rituals, music, and Paleolithic bead making can be fruitfully conceptualized as historical kinds individuated from other cultural activities and assuming a quasi-independent life and history, partially decoupled from those of other cultural activities or lineages.

All the examples discussed below share structural features that for us define such individuation. They all are embedded in processes of generational replacement, either by direct, material replication, or by indirect, mediated redevelopment and informational transmission, or by both. During the process of replication or reiteration, a historical kind retains a level of coherence and autonomy from other, cognate historical kinds. Coherence and autonomy are two sides of the same coin, the mechanistic stabilizing dynamic that helps to define the kind. And replication with coherence and autonomy not only maintains the kind but also sets in motion processes of historical change along lines of descent, which are determined through competition, among variant types within historical kinds, for representation in succeeding generations.

This return to the idea of selection, finally, calls for a special word on Peter Godfrey-Smith's Darwinian populations and individuals (Godfrey-Smith 2009). These are populations and individuals that can undergo selection - a very broad criterion that stands at some mediated distance behind all our kinds, both biological and cultural. For Godfrey-Smith Darwinian populations

๑ OPEN ACCESS - PTPBIO.ORG 
in biology can comprise genes, organisms, and perhaps species and some other groups. They might include also some products of human culture, though this reasoning takes him down a road traveled by many cultural selectionists toward a simplistic view of cultural change, which we will oppose below. The selectionist emphasis of Godfrey-Smith's argument reflects units-ofselection reasoning and even adaptationism, but at the same time it seems to point toward the discourse on biological kinds. It is productive in forging this juncture.

Nevertheless, Godfrey-Smith's sole criterion-the process that defines his Darwinian populations - is selection, and so this historical kind (if it be such) is at once more general and less specifiable than the kinds we will describe below. Our view recognizes a wider variety of processes from which kinds can arise. This individuation of kinds is not due to the nature of the processes by which they are replicated so much as to the cohesion brought about by functional integration of various sorts-by, again, the stable, causal operation of networked interactions. Our model of historical kinds points more clearly than Godfrey-Smith's Darwinian individuals toward processes beyond conventional selection that have not yet received their due in evolutionary theory.

Before we proceed to develop our argument, we want to offer a few words about the root of our collaboration, which, after all, is a somewhat extraordinary one between an evolutionary biologist and a musicologist and cultural theorist. Over the last several years, we have independently proposed models of evolutionary and historical origination. GPW published a book on the nature of morphological characters and their origin (Wagner 2014), and GT published two books on the origin of music and of human culture in general (Tomlinson 2015, 2018). It was our mutual recognition of the affinities between the mechanisms we had described that motivated our collaboration.

\section{Examples of Historical Kinds in Biology and Culture}

In this section we briefly discuss several examples of putative historical kinds from biology and the social and cultural sciences. We cannot, needless to say, cover all relevant examples. We consciously interleave examples from biology and the cultural sciences in order to highlight the similarities between biological and cultural historical kinds.

\section{Genes, functional systems, and selected lineages}

The gene is one of the four fundamental ontological units of biology, alongside the cell, the organism, and the species. While there are major disagreements about the ontological status of all of them, scientific practices in biology leave no doubt that biologists attribute great importance to them, including the gene and related subsidiary concepts. Genes are a repository, though not the only one, of biological information accumulated over evolutionary history. There are two complementary ways to introduce the gene concept, each reflecting a part of the history of our understanding of inheritance and evolution. These are the Mendelian or transmission genetic concept and the distinct concept arising from molecular biology. A third concept, the one used in molecular evolution, can be seen as a synthesis of the former two.

In the Mendelian concept, genes are thought of as quasi-atomic or discrete units of inheritance, or parts of the "germ plasma" that 1) cause a specific phenotypic difference (e.g., yellow or green coloration of peas) and 2) are transmitted independently from other such pieces of heritable material and remain unchanged during transmission between generations (except when mutations occur). This Mendelian concept bears an obvious similarity to other nineteenthcentury atomic concepts. It only makes sense, however, in species with sexual reproduction and 
recombination of their genetic material. Organisms without regular recombination, for instance bacteria, do not have "genes," at least not in the Mendelian sense of the concept.

Organisms without regular genetic recombination can, however, be considered to have genes according to the gene concept of contemporary molecular biology. In this concept the gene is no longer a simple atomic unit of inheritance but instead a complex functional system, with different parts ensuring the expression of the gene at the right time and place and allowing for different outputs in response to different inputs. For example, a gene that codes for a protein consists of a nucleotide sequence that can be translated into an amino acid sequence as well as sequence elements necessary to initiate and terminate its transcription onto an RNA molecule. A coding gene, then, is not a discrete material element, but a segment of a more extensive DNA molecule that includes a number of functional elements such that the segment is used by the cell to produce a certain protein. Mutations of this DNA segment are either neutral, i.e., functionally inconsequential, or they affect the production of the protein, thus affecting also those aspects of the organism that rely on the protein's function. As a consequence, in transmission between generations, the gene appears both as a unit of inheritance and a unit of function; but this dual appearance is an emergent property, arising from the relations of component parts of a system and not based on a unitary, structurally stable and delimited entity.

These two views of the gene, the transmission/genetic and the functional, are merged and connected to evolutionary theory in the gene concept employed in molecular evolution, the study of the history of genes and genomes (Grauer and Li 2000). In molecular evolution, a gene is viewed as a segment of DNA that forms a lineage of descent, the history of which can be traced by analyzing, across species and populations, the similarities of the nucleotide sequence of the segment. The inheritance of the DNA sequence characteristic of a gene is caused by the direct replication of DNA in the so-called "semi-conservative" mode of replication, meaning that each daughter copy of a gene consists of one strand of the ancestral DNA and one that was synthesized anew. Such replication leaves two copies of the original gene, identical except for rare mutations. Different variants of the same gene, or alleles, compete with each other for representation in the next generation. "Competition" here means that variants replace each other over time in the population rather than persisting in parallel, unless there is a so-called balanced polymorphism (see below). Competition occurs only between variants at the same locus in a genome. There is no competition with genes on other loci: different genes (as opposed to different alleles) do not compete, since their representation in the next generation of organisms does not depend on their being favorably selected over one another. They are guaranteed a seat at the table, so to speak, where "the table" is the genome in which, in general in a diploid species, there are exactly two "seats" for each genetic locus to place an allele. This number is not always fixed, since there can be occasional gene duplications (another chair is added to the table) or deletions (a chair is removed from the table). Constraining the number of copies of a gene locus per genome is the result of the complex cell biological machinery of chromosome replication and distribution during meiosis and mitosis.

In a genome, the inheritance-with-competition among the alleles and the absence of competition between different genes together form the basis for the quasi-independent evolutionary history of each gene; each, in whatever variant alleles arise, forms a lineage across this history. Replacement can occur between functionally equivalent variants, in the process called "neutral evolution" or "genetic drift," but natural selection involves replacement on the basis of functional differences between the alleles. It is evident, then, that the allele lineages created in natural selection and drift depend not solely on replicated segments of DNA, but in addition on the functional interdependencies among the different parts of the genomic region that we recognize as "the gene." 
Of course, there can be more complicated situations that are not captured in this simple model, for instance the possibility of stable polymorphisms, where two alleles are maintained by natural selection in the population because the heterozygote genotype is more fit than either of the homozygote genotypes. In such cases, for example the stable polymorphism of the sickle cell anemia allele of hemoglobin in areas with malaria infestation, each allele has its own evolutionary history for as long as the stable polymorphism is maintained. Stable polymorphisms can be immensely long-lasting, as the polymorphism at the alcohol dehydrogenase locus in Drosophila melanogaster demonstrates (Hartl and Clark 1989). But these complications do not change the fundamental structure of the gene concept in molecular evolution.

A comparison of genes within particular species' genomes reveals that some genes within a genome can be more closely related to each other than to other genes in the same genome; instances are the different kinds of Hox genes, i.e., transcription factor genes that control parts of bilaterian animal development (Gehring 1998). The DNA sequences of different Hox genes are more similar to each other than each of them is to other genes in their respective genomes. These similarities point to their evolutionary relatedness, suggesting that they originated by some form of copying mechanism, which left multiple copies of one ancestral gene in different parts of the genome of an ancestral organism. Note that these copies, unlike the allelic copies discussed above, are truly different genes, which do not compete with each other because they are located at different loci in the genome.

The fact that genes can be more closely related to each other than to other genes in their own genomes points to evolutionary events in which a gene was duplicated and each copy subsequently took on its own, quasi-independent evolutionary history or lineage of descent. Thus individuation of the sort that gives rise to historical kinds can occur at the genetic level. Genes can show the patterns of evolutionary change that we argue are characteristic for all historical kinds, namely one process of evolutionary modification along a line of descent, and another process that leads to the origination of new lines of descent. The latter is much rarer than the former. In the case of genes, the origination of a new line of descent comes about through gene duplication or gene fusion. The evolutionary history of the new genes thus created, their loss or maintenance, is complicated and cannot be adequately dealt with here ( $\mathrm{Li} 1985$; Meyer and Schartl 1999; Kondrashov, Rogozin, et al. 2002; Van de Peer, Maere, et al. 2009).

In general, then, the conventional story of gene duplication, mutation, and natural selection outlined above omits an aspect of the biology that explains the historical, functional cohesion of what molecular biologists think of as genes. Insertions and deletions of small fragments of DNA are frequent occurrences in evolution, and so any DNA segment might diffuse into the genome and eventually become untraceable, as happens with large chunks of intergenic DNA. In the case of functionally relevant parts of the genome, however, the functional integration among the parts of a gene creates an emergent cohesion that prevents the loss of identity over evolutionary time. This integration manifests itself in various ways and mechanisms. For instance, an insertion or deletion in a coding region of a gene that does not respect the reading frame (which maps codons, triplets of nucleotides, to amino acids) has a high chance of leading to a non-functional or even toxic protein product. In other cases, a protein coding region might acquire non-coding sequences, so-called introns. But this is only tolerated by natural selection if the intron contains sequence elements that guarantee the removal of this sequence by splicing from the transcript before it is used for making a protein. Even the sequences around the coding region have to meet selective expectations, such that the transcription is initiated at the right time and place, the translation is properly terminated, and the stability of the mRNA is appropriate for the RNA turnover rate and adequate for the cell's metabolism. All of these and other mechanisms 
ensure that a functional part of the genome remains a recognizable and coherent unit of genomic change.

\section{Historical kinds in the evolution of culture}

Cultural kinds, like biological kinds, are historical entities that emerge through evolutionary processes as units of function, forming quasi-independent lineages of these units. Discerning cultural kinds is a powerful strategy for understanding biocultural evolution. In this and two more cultural sections below we will show why this is so.

All animal cultures are founded on fundamental processes and adapted capacities that underlie these processes. Two basic processes define culture: learning and transmission (Boyd and Richerson 2005; Richerson and Boyd 2005; Sterelny 2012). Culture is the process in which an organism learns in its life experience such things as social patterns, behaviors and activities, ideas, or manipulations of materials and transmits this learning to other conspecifics, especially those in the succeeding generation. The prominence of intergenerational transmission in this definition has led to a large literature on cultural selection, viewed as a process analogous to natural selection (e.g., Cavalli-Sforza and Feldman 1981; Boyd and Richerson 1985; Runciman 2009; Mesoudi 2011). The broad sweep of the definition, meanwhile, is necessary in order to take in both the deep history of culture among hominins and the cultures of some non-human animals in the world today (for example, some songbirds, cetaceans, monkeys, and apes).

The adapted capacities underlying these cultural processes include attention, the ability to focus on specific stimuli from the external world while ignoring others (Knudsen 2007; Bloch 2013; Haladjian and Montemayor 2015). They include also some considerable store of episodic and semantic memory and at least a rudimentary shared intentionality or "theory of mind" (Carruthers and Smith 1996; Tomasello, Carpenter, et al. 2005). These in turn, in most models of cultural origins, are posited to give rise to joint attention shared between conspecifics, to enable imitative behaviors, and to support complexities of social interaction or "social intelligence" of varying degrees (Tomasello 1999; Boyd and Richerson 2005; Sterelny 2012).

Repeated cultural gestures, formations, activities, and so forth can form systems of cultural content defined by the functions emergent from the networked linkages of their parts. It is these systems, not the adaptations required for culture to arise, that in our view form cultural kinds and, when they are transmitted across generations, lineages of cultural kinds (Renn 2020; for an adaptationist alternative view, see Aunger and Curtis 2015). In their system-defined functions, cultural kinds resemble genes as conceived in modern molecular biology and molecular evolution. They do not resemble the atomic material units of the older Mendelian conception, and assimilating culture to this Mendelian view has been a common misstep since Richard Dawkins introduced the term "meme" to denote a discrete bit of culture (Dawkins 1976; Blackmore 1999). The analogy of the contents of culture to the Mendelian gene reflects not merely an outmoded understanding of the gene but an inadequate understanding of cultural development and change, and its shortcomings have been repeatedly diagnosed (Sperber 1996; Deacon 1999; Bloch 2000). The organization of cultural contents into functional systems is basic to culture, just as functional organization is basic to the identity of genes.

The replication of cultural systems through generations is not, however, "semi-conservative" copying in the manner of genetic replication-not, at least, in the cultures of Homo sapiens over many tens of thousands of years. Because the content of culture is in some degree ideationalthe product, in a minimal description, of complex neural networks interacting with sensory input - this content tends to vary incessantly rather than being preserved faithfully. These variations are not so large as to threaten the functioning of continuous lineages of cultural kinds, 
and here, as in Boyd's HPCs discussed in the introduction (Boyd 1999), we see the need for a blurriness and pluralism of definition in discerning lineages of cultural kinds. Cultures of non-human animals and of some now-extinct hominins display less local variation and more faithful intergenerational replication than the complex cultures of all modern humans. Bird cultures exemplify this (Gardner, Naef, et al. 2005; Slagsvold and Wiebe 2011; Tchernikovski and Marcus 2014), as does the long-lived Acheulean lithic technology, stably passed on among hominin species for more than a million years (Wynn 2002; Klein 2009).

All animal culture is an outgrowth of more basic and widespread animal sociality, which is a supra-individual phenomenon that plays itself out in relation to the environments inhabited by social species. Cultural forms and gestures are all instances of social niche construction, and the emergence of historical kinds in culture starts from this central plank in the platform of the EES (Odling-Smee, et al. 2005; Laland, Uller, et al. 2015). The interaction systems of cultural kinds typically involve such social niche-constructive dimensions as communication, behaviors surrounding social events such as mating and death, providing sustenance for the group, and technology. Niche construction, in addition, features feedback loops extending between populations and their environments, and such "reciprocal causation" (Laland, Uller, et al. 2015) is central also to the interrelations of the components of cultural systems; we offer an example below. We will see, however, that an emphasis on feedback alone is not sufficient to describe fully the biological and cultural implications of reciprocal causation. We need in addition to understand the emergence of control mechanisms that come to channel the course of historical kinds; such controls are discussed in the final sections of this paper.

The individuation of a cultural kind depends on the joining of system components in stable ways that transform them by virtue of their participation in the system as a whole. The transformation of the components, which marks the individuation of the kind, involves mutual relations between them and the system, since the system could not arise without the components, while they could not be transformed without the systemic function.

An example of such individuation is offered by our first instance of a cultural kind: bead making, an activity widespread among Middle Paleolithic Homo sapiens reaching back more than 100,000 years (Vanhaeren and d'Errico 2006; d'Errico and Vanhaeren 2007; White 2007). Beads-materials drilled through for hanging on straps, hair, or clothing-were produced at the cost of considerable effort (White 2007), presumably because the ornaments they structured served as markers of social difference of one sort or another, in societies whose growing complexity made such marking advantageous. Beads reflect the formation of a cultural system out of several components: materials (shells, teeth, ivory, etc. for the beads; straps or clothing to hang them on); technologies and tools (drilling with awls or burins); and complex social or kinship forms differentiating ranks and statuses. Some of the components are material, some ideational. All the components, even as they construct the system, are transformed by its function: shells or teeth, once only waste-products of food harvesting, are now insignias of social position; a drilling technology is turned to a new use to produce these insignias and thus altered in its technique and scope; and ideational social status is now made visible in material form through new kinds of manufacture and effort. The resulting beads can engage in different forms of social structuring: status marking, tribal and familial affiliation, gender roles and more. This relative independence from a particular role signifies the quasi-autonomy of this cultural kind from others.

Competition among historical kinds in culture can be seen, across the evolutionary timespans through which they persist, as biocultural selection of them. Analyses of cultural selection since the 1980s have used the mathematics of population genetics to model the changing frequencies of isolated cultural traits, in effect treating units of culture as if they were genetic al-

๑ OPEN ACCESS - PTPBIO.ORG 
leles (Cavalli-Sforza and Feldman 1981; Boyd and Richerson 2005). Such analyses, even when focused on cultural innovations (Shennan 2001; Richerson, Boyd, et al. 2009), are ill-equipped to capture the interlinked specificities of content characteristic of cultural systems. They do not address the question of how such contents coalesce into robust functional systems, and hence they cannot explain the origination of historical kinds. These functional systems make a slightly larger appearance in the modeling of cultural niche construction offered in the EES, but here too the methodological limitations of formal modeling are felt (Odling-Smee, Laland, et al. 2003; Laland, Uller, et al. 2015).

By including the interrelation of contents of cultural systems in this picture, we complicate and finally revise these earlier, simpler models. We add to them a functional dimension that redefines cultural patterns and canalizes their evolution, and we focus on the specific mechanisms that work together to fix such systemic functioning in persisting lineages. In our example of bead making, cultural selectionist accounts might posit selective advantages accruing to groups able to muster more complex social structure than other groups, and niche-constructive accounts might isolate the use of material signs of rank or position in organizing such complexity. But neither kind of account can describe the emergence of a historical kind whose function alters the potency of the marking of social difference itself and channels this new force into further cultural evolution.

\section{Species: their nature and origin}

Debate over the nature of biological species is complex and has a long history. This issue was clarified in the 1990s by the discerning of homeostatic property cluster (HPC) natural kinds described in our introduction (Boyd 1999; Griffiths 1999; Brigandt 2007). Conceiving species under this rubric seems to us particularly fruitful for four reasons: its turn away from essentialism to historicity as a defining feature of many kinds of kinds; its reliance on components causally networked that maintain the identity of historical kinds; its realization that these networks are not restricted to internal systems in a kind but can extend out from it as relational causal networks, involving aspects extrinsic to a kind; and its epistemological aspect (Boyd's "accommodation" to a "disciplinary matrix"), which forefronts the pluralist definition of kinds needed in differing research programs. Especially in the light of this last feature, the question of the origin of species exemplifies the diversity of explanatory strategies that evolutionary biologists have employed when faced with questions of origination. In this section we will not review the history of the species debate but briefly position our view of historical kinds in regard to it.

The species concept reflects the fact that living things overwhelmingly come in distinct clusters of similarity. The nature of species is that they form population level units of evolutionary change and for that reason are genetically and often phenotypically distinct from other species. Oak trees and blue whales come with very few intermediate forms, and this is the rule despite the existence of so-called "sister species" (Mayr 1963) that look, to the human eye, very similar and "polymorphic" species such as honeybees, Apis mellifera, and Homo sapiens that consist of phenotypically distinct subpopulations but still belong to a single species. While biological species were once considered paradigmatic examples of "natural kinds" (Putnam 1975; Kripke 1980), philosophical views requiring an essential physical property to distinguish instances of different natural kinds cast doubt on this status. In this essentialist view, only kinds that could figure in exceptionless, eternal laws were considered to be natural kinds. Biological species could not meet this requirement. A major advance in the face of this essentialism was the notion of species as historical individuals (Hull 1978, 1980). In this view species are evolutionary entities 
with their own beginning, history, and, eventually, end (Ghiselin 1974, 1997). Their specific histories unfold largely independently from one another, which justifies their delimitation.

This "species as individuals" conception, however, hardens a distinction between individuals and kinds and does not offer any processual explanation for the delimitation of a species. A considerable softening of the individual/kind opposition and a turn toward causal processes were both achieved in Boyd's HPC natural kinds (Boyd 1999). Motivating this development was the existence of many concepts in all sciences that play a role in explanatory projects but do not meet the strict, essentialist criteria for natural kinds. To deny the role of these concepts in scientific inferences and explanations seems to eliminate a large portion of scientific knowledge from consideration as "really" scientific; to accept this role, on the other hand, seems to grant to the concepts thus used at least a strong epistemological status as kinds. But the status is more than sheer epistemology, since the usefulness of such concepts in scientific explanation depends on the causal relations they reflect in the world and among the components they comprise. Boyd's HPC natural kinds include, ultimately, any concepts that capture a causal structure relevant for a disciplinary project of knowledge acquisition. This idea triggered a reconsideration of the species concept because it recognized that there are causal processes that separate different species from each other, for example genetic incompatibility (Mayr 1963) and demographic replaceability (Templeton 1989); yet at the same time it allowed for the fact that species evolve (Boyd 1999; Griffith 1999; Brigandt, 2007).

In an idealized model, a biological species consists of a lineage of populations that evolve quasi-independently from other such sets of populations, regardless of whether this is due to genetic incompatibilities, as in the case of sexually reproducing species, or to ecological or demographic factors. A consequence of this view is that we need to distinguish two distinct evolutionary processes similar to the ones we distinguished above in the evolution of genes. On the one hand is the evolutionary transformation of populations along a particular lineage, called in an older literature "anagenetic" evolution. On the other hand is the splitting of a lineage to form two independent lineages, or two species. This process has been called "cladogenetic" evolution (Hennig 1966) and is synonymous with speciation. The study of each of these processes requires different research programs and different sorts of explanations, as we noted in the introduction.

Anagenetic evolution can be largely explained by the two major population genetic processes, natural selection and genetic drift. Natural selection explains the evolution of adaptations, while genetic drift explains random change, which nevertheless can lead to directional changes such as the trends in genome organization noticed in recent decades (Lynch 2007). In contrast, to understand the origin of a new species we need to identify processes that lead to the formation of two quasi-independently evolving populations. Many different modes of species separation have been described, and finding and analyzing these processes is still an active focus of biological research. They include geographic isolation and the random acquisition of genetic incompatibilities, genome duplications, hybridization, disruptive selection and more. When two species emerge from one, the genomes of each become incompatible due to so-called "epistatic effects." Whatever the process involved in the separation, the status of a population as a biological species depends on its ability to maintain such a quasi-independent status in terms of evolutionary change.

As we made clear in the introduction, we believe that this is a general feature of historical kinds: they are what they are because of the role they play in evolutionary/historical processes, not because of how they took on a form that could assume that role. This general feature, then, characterizes not only species but also our other examples of historical kinds, biological and cultural. Moreover, once a species has attained quasi-independence, its historical coherence is maintained through processes similar to those that maintain the historical coherence of genes,

๑ OPEN ACCESS - PTPBIO.ORG 
cell types (see below), and cultural kinds, namely the operation of functionally integrated mechanisms. In the case of sexually reproducing species, for example, the integration results from the requirement that haploid genomes from the two parents, united during fertilization, be functionally compatible.

\section{Coherence, autonomy, and external systematization in cultural systems: ritual}

Parallels between the persistence of genes and species and the persistence of cultural systems are apparent in the wake of this discussion. Like genes and species, historical kinds in culture are units of evolutionary change (in this case, biocultural evolution, Sterelny 2012; Tomlinson 2018; Renn 2020); and they lead quasi-independent histories. Like genes, they take on these features by virtue of their systemic structure - the interlinking of components that enables them to assume certain functional roles within a culture, as in our example above of bead making systems. Selection for the function fulfilled by the system as a whole brings about stable persistence. It is not, for example, a particular flint-knapping gesture in an ordered sequence of such operations that is selected, but the functioning of the tool that results from the whole sequence. This means that the components of a cultural kind, like the components of a genetic system characteristic of a species, must stabilize a coherent interaction in order for the kind to persist in recognizable form. They must maintain the networked interrelations that give rise to the function of the system, which in turn shapes its selective history.

The maintenance of the coherence of its systemic network renders a cultural historical kind recognizable across evolutionary history. The coherence also marks off cultural kinds from the cultural contexts in which they occur, giving them varying degrees of autonomy. This is clear in the case of the tool making system just mentioned, or in the bead making discussed above. There the shell-as-insignia occupies a place in a bead-making culture that is determined by its relations to the other elements of the system and for this reason set apart from the shellas-byproduct of harvesting. A similar autonomy is clear also in many different cultural kinds involving communication in non-human cultures. The "songs" of songbirds, for example, are complex patterns of vocalized sounds with roles in territorial marking and mate attraction. As a biocultural system making up a cultural kind, these songs comprise an intergenerational, social pedagogy, a sonic medium, distinctive combinatorial structures in their design, and a dedicated biological substrate in the birds' bodies and brains that enables their learning, production, and cognitive processing (Beecher and Burt 2004; Marler and Slabberkoorn 2004; Nottebohm 2005; Fiete and Seung 2009). These join together to make birdsong coherent and autonomous from other bird behaviors, and this systemic assemblage enables the songs to fulfill the functions that have evolved in their selective histories.

Such coherence and autonomy are evident in the case of ritual in hominin societies, and we can consider ritual a class of historical kinds that is pervasive in human culture. A ritual comes about through the formation of a system of gestures and expressions - of practicesthat sets itself apart from the quotidian expressions and gestures around it. The construction of such autonomy is characteristic of the process of ritualization (Bell 1992). Thus a puberty rite, a wedding, or a liturgical ceremony asserts its autonomy in the performance that fulfills its function-or, better, it fulfills its function by asserting its autonomous performance.

But rituals also call for something more, another defining trait of this class of kinds as a whole. The internal system of gestures and expressions that makes up a ritual must be repeatable and, moreover, repeatable in specific, socially determined moments. This means that the ritual system must point in systematized ways beyond itself - that ritualization is a process pointing both inward toward an enclosed system and outward toward a fixed relation with institutions, 
power structures, and cosmologies (Tambiah 1979; Bell 1992). The system that makes up the ritual involves, then, not only intrinsic causal relations that set apart the ritual practice but also structured relations reaching beyond it to those broader cultural dimensions. The mutual transformations of cultural components and system comprising them, and hence the individuation of a ritual historical kind, depend on this dual systematization.

The circumstances that evoke the full, dual systematization of ritual in modern human societies, and that must have evoked it also among our ancestors, are often life-cycle events consequential in marking the structures of a society and its place in the world. They include today the marking of kinship and affiliation, of rites of passage into maturity, of pair-bonding, of death, of successful communal provisioning, of shared belief, and the like. Rituals marking such events are very ancient, and it is likely that ritualization predated Homo sapiens in deep hominin history. Evidence for this is the complexity of social coordination that archaeologists have reconstructed among several earlier hominin groups including Homo heidelbergensis and neanderthalensis and our direct ancestors in Africa (Gamble 1999; McBrearty and Brooks 2000; Pope and Roberts 2005). The emergence and individuation of rituals, in other words, were probably early byproducts of the general increase in the complexity of social organization in hominin groups.

This pre-sapient emergence makes it also likely that ritual kinds took shape before language and music, features of all sapient cultures today, assumed their modern forms. Ritual without modern language may seem a puzzling concept, but to see this likelihood we need only picture social complexities among hominins as far back as half a million years ago, which involved pedagogies of tool making, divisions of labor in organized hunting or scavenging, communal sharing of the resulting spoils, and other similar behavioral patterns. The absence of modern language in such societies need not have blocked the coalescing of ritual, because they possessed well-developed vocal and bodily communicative resources referred to today as "protolanguage" or "protodiscourse." Long before the syntax and lexicon of modern languages appeared, hominin ritual could have relied on these communicative means and even canalized their own further development toward modern forms. We return to protodiscourse, language, and music below.

\section{Cell types as biological historical kinds}

All life depends on cellular organization, including biological entities that are not cells themselves, like viruses, which are parasites of cellular life. The most fundamental reason for this fact is that life only exists in a state of thermodynamic disequilibrium with its environment, and this necessitates the maintenance of chemical gradients between the inside and outside of life forms. Cells are the fundamental, i.e., atomic, unit of life, and, in our world, only originate from other such units (omnis cellula ex cellula, Virchow 1860). As the fundamental unit, cells also form the building blocks of so-called higher forms of life, such as animals and plants. As cells arrange to form multicellular units of life, i.e., organisms, they differentiate into distinct cell types, dedicated to different functions. Probably one of the first such differentiations was that between cells dedicated to somatic functions (digestion, locomotion, etc.) and those specialized for reproduction (Buss 1987; Michod and Herron 2006). The diversification of cell types is one of the major avenues for the evolutionary increase in organismal complexity (Valentine, Collins, et al. 1994; Arendt, Musser, et al. 2016). About five to thirty cell types may exist in the anatomically most primitive free-living animal (Trichoplax adhaerens, Smith, Varoqueaux, et al. 2014), while about 500 are recognized for humans and other mammals (Vickaryous and Hall 2006) — a number that is most likely an underestimate.

Only in recent years has it been fully recognized that cell types form distinct, individuated lineages of descent (Arendt 2008). This means that they are historical kinds in our sense of the

๑ OPEN ACCESS - PTPBIO.ORG 
term, and indeed they show formal properties common to other biological historical kinds. In addition to forming lineages of descent, they undergo modification along those lineages and can originate new lineages by lineage splitting, like species during speciation, and by hybridization, in cell type fusion (Wagner 2014, chapter 8; Arendt, Musser, et al. 2016). This conceptual re-evaluation of cell types as phenotypic units of evolutionary change came about through the realization that cell types can be homologous across large phylogenetic distances. To say that cell types in two species are homologous is to hypothesize 1) that the most recent common ancestor of these two species also had the same cell type, 2) that there are two unbroken chains of inheritance connecting the cell type in the last common ancestor to the cell types in the derived species, and 3) that the history of cell type change is tracable (DiFrisco, Love, et al. 2020).

The recent discovery of cell-type lineages was driven in part by the availability of molecular signatures that allowed identification of homologous cell types even in cases where the morphological and functional phenotypes have become unrecognizably different. In these cases the cells have undergone a change of function in the course of evolution, for example, a change from a photoreceptor cell to an interneuron (Arendt 2003). From this it is clear that cell types are analogous to genes, species, and cultural types at a formal, phenomenological level, that is, they are units of evolutionary change that form lineages along which take place both modifications and rare events of origination (Arendt 2008; Arendt, Musser, et al. 2016).

A difference between the origination of species or genes and that of cell-types arises at the proximate level, in their mechanisms and modes of inheritance. Genes form lineages of descent based on direct replication of the DNA molecules, in which the descendant copies of the gene have material overlap with their mother copies (Griesemer 2000) and arise from the functional cohesion imposed on parts of the genome recognized as genes. Species arise from the separation of populations, where there is a continuity of populations from the ancestral species to the two descendant species. In contrast, cell types do not show any direct form of replication between generations, since a cell type in a parent does not give rise directly to that cell type in the offspring. Nerve cells from parents, for example, do not directly generate nerve cells in the baby. Instead a process of developmental mediation is required: in each generation, the specialized cell types of the offspring arise through a process of development and differentiation from undifferentiated cells arising from the zygote. In a structural sense, this is similar to the mediation required in a lineage of cultural kinds: the cultural kind too is not directly replicated, but needs to be regenerated by each new generation through the mechanisms of transmission characteristic of culture.

This developmental mediation leads to a number of conceptual difficulties, in particular with respect to the ontological status of cell types. For Peter Godfrey-Smith (personal communication), for example, cell types cannot be historical individuals analogous to species and genes, because they do not directly replicate. Therefore, though it might be granted that we can represent the relationships among cell types in different species in a way similar to a phylogenetic tree, this representation, Godfrey-Smith argues, is illusory. In this argument, however, phenomenon and explanation are conflated. The phenomenon is the treelike pattern of diversification found in genes, species, and also (putatively) in cell types. One model for the formation of the tree is direct replication, which can explain the homology of genes and the relatedness of species. But to say that a phenomenon is an illusion because one particular explanation for its formation does not apply is to give the explanatory model an inappropriate ontological status. What matters is the fact that the tree-like pattern of evolutionary diversification of cell types shows that they behave as evolutionary individuals. How they came to do so-whether in the same way as genes and species-is irrelevant. 
If cell types are historical kinds in biology, we require an explanation as to how the individuation proper to them comes about-how, that is, some cells are individuated from other cells in the same body with respect to their development, function, and evolutionary history. If there is no direct replication and transmission of cell type identity from generation to generation, what then endows a cell type with the ability to have its own evolutionary history, quasi-independent from that of other cell types? Some of the answer, certainly, will be and has been found in the genome, but the variability, among species, of the genetic determinants of cell type development renders this answer insufficient (Arendt, 2008; Wagner 2014, chapter 8). The full answer to this question has not been settled, but what we have learned in recent decades about the molecular biology of cell-type differentiation and the evolution of gene regulatory networks suggests a plausible model.

Different cell types usually perform different functions in multicellular organisms. To be able to do so they express a different, though partially overlapping, set of genes than other cell types. Different genes lead to different gene products, such as enzymes, non-coding RNA, and cytoskeletal proteins, and these determine the cell types' physiological and morphological phenotypes. The genes that produce the phenotype of cell types can be called "effector genes." But through what mechanisms do different cell types come to express these different sets of effector genes? At one level the answer lies in the diverse signals a cell receives from other cells in the embryo, which determine its ultimate fate. In many cases, however, the signals, which can be small molecules such as steroid hormones, peptides, or ions, do not directly regulate the effector genes, but instead activate a different set of genes, many of them coding for transcription factor proteins. Several slightly different models suggest that these genes form a small regulatory network, variously called a kernel (Davidson and Erwin 2006), cell type identity network (Wagner 2007, 2014), or terminal selector module (Hobert 2011). The genes in the cell type identity network, once activated by the differentiation signals, then 1) regulate the expression of effector genes, and 2) suppress, directly or indirectly, the activity of alternative cell type identity networks and their cognate effector genes.

This forms a three-layer model of cell type development, encompassing signals, cell type identity network, and effector genes and/or effector modules. Using this model, we can devise a scenario for the structure of the gene regulatory network that explains the evolutionary individuation of cell types. In order to do so, we need to add one additional feature, critical for what follows. The transcription factor proteins produced by the genes of a cell type identity network do not act singly, but form a physical complex that has been called a "core regulatory complex" or CoRC (Arendt, Musser, et al. 2016). This CoRC is the actual molecular entity that regulates the gene expression specific to a particular cell type. Cell differentiation signals lead to the formation of this CoRC not only through their influence on gene transcription but also by causing post-translational modifications of the transcription factor proteins, modifications such as phosphorylation, acetylation, ubiquitination, and others. These CoRCs are evolutionarily highly conserved and rigidly associated with the evolutionary lineages of their cognate cell types (Brunet, Fischer, et al. 2016).

A CoRC regulates the expression of effector genes by binding to specific cis-regulatory elements (CREs), segments of DNA often proximate to their associated effector genes (for instance the mechanisms determining motor neuron identity, Lee, Lee, et al. 2008). In other words, in a cell type endowed with its specific CoRC, any gene with an appropriate CRE can be expressed. An effector gene can, in evolution, come under the control of a CoRC through the insertion of a transposable element, which can carry ready-made transcription factor binding sites; this scenario has been demonstrated in many cases (Emera and Wagner 2012; Lynch, Nnamani, et al. 2015). The implications of this are profound: the phenotype of a cell type can evolve 
through the acquisition or loss of genes regulated by a cell type-specific CoRC. The historical continuity of a cell type identity is mediated through the evolutionary continuity and conservation of its CoRC.

This model amounts to a mechanistic explanation of how a cell type can maintain its identity and thus historical independence from other cell types, and at the same time evolve a more or less arbitrary phenotype. The cohesion of the cell type, over evolutionary time, can be explained by the coevolution among the transcription factors forming the CoRC. Due to the continuous expression of the CoRC, cells are able to change their phenotype in a gradual manner, by the stepwise addition or loss of effector genes under the transcriptional control of the CoRC. This feature makes the evolutionary history traceable in spite of changes of cell phenotype, through tracing either the expression of the CoRC itself (which is technically difficult) or the gradual change of the cell phenotype.

This scenario is a model only-a schematic simplification that serves to illustrate how cell types can have historical continuity and quasi-independent trajectories of evolution and to explain their tree-like pattern of evolutionary diversification. It suggests, nevertheless, that cell types are endowed with a molecular machinery-i.e., core-regulatory complexes of transcription factor proteins - that enables differential expression of effector genes. It suggests also that this regulatory machinery enables the cell type-specific evolution of the cell phenotype, leading to the evolutionary modification of cell types. The evolution of novel CoRCs or cell type identity networks can thus originate a novel cell type identity, in turn splitting the evolutionary fate of a cell population and leading to two new cell types. The two sister cell types form independent lineages of evolutionary modification because the cell type specific CoRCs control different gene sets having different cis-regulatory elements responsive to different $\mathrm{CoRC}$. The functional integration of the CoRC ensures its long-term persistence by means of a specific trans-regulatory activity. This mechanistic scenario offers an explanation for the diversification of cell types along trees of phylogenetic relatedness in which direct replication of cell types plays no role. It is important to note, however, that this model is only one possible mechanistic realization and that it is in general better to think in terms of multiple character identity mechanisms rather than limiting the concept to a particular molecular realization (DiFrisco, Love, et al. 2020).

\section{Control systems and epicycles in the formation of cultural kinds}

The model of cell type effector genes, CoRCs, and identity networks described above suggests that a functional system can be endowed with regulatory or control mechanisms that shape or determine its operation. Such mechanisms can assume long-lived stability, coherence, and autonomy. The stable CoRCs, guiding the expression of effector genes with their cis-regulatory elements and thus the differentiation of cell types, show these features. In our view, understanding such emergent control mechanisms represents an important extension of the emphasis placed on feedback networks in the EES. In systems theory, mechanisms controlling the feedback loops of a system but not directly a part of those loops are known as feedforward elements. (Feedforward in this usage is not to be confused with positive feedback.) We can think of control mechanisms such as CoRCs as elements residing within a functional system that, while only partially autonomous from the system that gave rise to them, come to show such feedforward dynamics by controlling the expression of effector genes. Another example might be allostasis in stress response (Zhang, Pi, et al. 2010)—which in its mechanisms resembles the "antifragility" recently analyzed in many cultural systems (Taleb 2012).

Emergent control mechanisms of a similar sort arise in cultural systems. Here, as in CoRCs, they take on heightened stability and autonomy, which in this case are played out across the 
biocultural evolutionary situations in which they are formed. In their heightened autonomy from the cultural kinds that generate them, they exert feedforward influence, controlling effects on the feedback cycles involved in biocultural evolution; for this reason Tomlinson has called them cultural epicycles (Tomlinson 2015, 2018). Epicyclic mechanisms are formed especially in complex animal cultures (though they are arguably not unknown in simpler ones), and much of the dynamism of the recent biocultural evolution of hominins may be traced to their operation in the formation of new historical kinds. What are the general conditions under which they arise?

We have seen that all culture is niche constructive- that is, it manifests itself in the environmentally situated sociality of the animals that create it. The literature on niche construction has treated extensively the feedback cycles between culture and biology. Usually they are viewed this way: cultural practices of a population alter the environment in advantageous ways, giving rise to altered selective pressures on the genomes of the population; selection is favored for genes enabling or fostering the practices that advantageously alter the environment, and this pushes the population as a whole toward enhanced culture-making capacities (Odling-Smee, Laland, et al. 2003; Laland, Odling-Smee, et al. 2010; Laland, Uller, et al. 2015).

Epicyclic mechanisms add a new dimension to this model. By virtue of their feedforward impact on the feedback cycles of biocultural evolution, they drive culture in a specific direction, not only redoubling its niche-shaping force but also biasing its outcome. They can operate this way because of their heightened coherence, autonomy, and stability, generated from the cultural system itself in its interactions with the niche. In this dynamic we see a parallel to the systemgenerated regulatory networks that control the individuation and persistence of cell types. In each case, one of the results is a tightening of the coherence of the functional system, whether cultural or genetic/epigenetic; further consequences in each case can be the strengthened autonomy of the system as a whole from surrounding systems and the increased likelihood of its persistence.

This begins to describe the dynamic by which cultural epicycles give rise to new kinds, but there is another aspect that is central to it. Because culture is niche constructive, all historical kinds that are individuated in it stand in a relation, more or less mediated, to the affordances and constraints of the environments in which they operate. In reshaping the niche, cultural historical kinds do not merely reflect passively these environmental conditions, but instead alter them in more or less dramatic ways. The epicyclic origination and individuation of a historical kind is an especially marked event in this reshaping of environmental conditions, in which factors that had not previously functioned as affordances or constraints begin to do so. Environmental factors previously insignificant in biocultural evolution take on a new, powerful significance because of the nature and function of the coalescing cultural system itself. It is as if this system were probing a biocultural search space, bumping up against new aspects of this space in its exploration. The system, then, takes on an altered identity in tandem not only with its alteration of its niche but also with qualitative shifts in the range of external factors relevant to its niche construction. Both coalescing system and reshaped niche can then "lock" into a new, stable conformation that facilitates further biocultural evolution along certain lines rather than others. This mutual shaping of regulatory systems within culture and the relations between culture and its niches has parallels in the relations of constructed niches to gene regulatory systems (Laubichler and Renn 2015). It is also another manifestation of the extrinsic relations that can come into play in the determination of the systems that define historical kinds, which we have underscored above in our examples of ritual and cell type identity networks.

An example will clarify this epicyclic model. It takes the form of a set of linked inferences aiming to explain the emergence among hominins of some capacities basic to modern human

๑ OPEN ACCESS - PTPBIO.ORG 
language and music (for fuller accounts, see Tomlinson 2015, 2018). Language and music can each be considered a single cultural kind, not a class of cultural kinds, like ritual. This is true notwithstanding the thousands of human languages in the world today and the many more that have come and gone, and the innumerable musical practices humans have devised. The grouping of all languages and musical practices into two cultural kinds is warranted by the specificity of the components that determine not merely one but all human languages, and not just a single musical practice but all musical practices. No such specificity of components extends across all rituals. The components include, in language, the dual combinatorial structuring of discrete elements-phonemes into words, words into propositions-and, in music, discrete pitch processing and metric or "beat-based" entrainment. These features and others make up internal systems that structure human language and music and are likely due to historical homology rather than independent origin (Balari and Lorenzo 2013); in each case, the structure enables the communicative function.

Language as a whole and music as a whole thus are distinguished in their particular functional systematizations from other communicative means. Indeed, in understanding language and music as individual cultural kinds it helps to see them in the broader perspective of the cultural communication of many animals - a class of cultural kinds that extends well beyond our species and includes birdsong, the click codes of sperm whales, the songs of humpback whales, and some communicative gestures of great apes (including some vocalizations- "gesture-calls," as one anthropologist has usefully named them, Burling 2007). Note that this class does not include all animal communication, but cultural communication only, that is, communication employing means and expressions learned and transmitted to future generations.

But how were language and music, distinctive human historical kinds of communication, individuated in our deep history? In each case, several cultural epicycles arose that not only biased ongoing cultural evolution but also redefined environmental or ontological constraints on communication. There is space here to outline only one of these, which militated toward the distinct forms of discrete cognitive processing that characterize language in one fashion and music in another (for more, see Tomlinson 2015, 2018).

As early as half a million years ago, as we remarked in the discussion of ritual, at least some hominins lived in social groups complex enough to require well-developed communicative codes. These protolanguages or protodiscourses, to judge from archaeological reconstruction and the communication of apes and monkeys in the world today, involved varieties of bodily gesture and vocalization (Bickerton 1990; Donald 1999; Burling 2007; Bowie 2008; Tomasello 2008). The communication achieved was indexical, that is, its meanings depended on relations of pointing, contiguity, or causal connection between vocal and gestural signs and their objects. This limited the range of the communication and rendered it dependent on its immediate context, a condition that still plays fundamental roles in language today and is referred to as deixis.

The development of indexical protodiscourse progressed in tandem with the sociality around it, the one nudging the other toward greater complexity as the niche-constructive advantages of such complexity came to be felt. This led to an increase in the number and variety of the signs employed. In vocalization - to judge, again, from non-human mammal vocalizations in the world today - the indexes were at first deployed along a graded, analogue spectrum, with continuously modulated intonational shapes, amplitudes, onsets and decays, and timbral patterns. But the multiplication of such indexes brought them up against a new constraint, not relevant to simpler protodiscourse: the ontological constraint, on any graded spectrum, that increasing the number of events will decrease the distance between them. Each index, as their number multiplied, became more and more like the ones near to it on the spectrum. Communicative clarity was compromised as the number of signs increased. 
This new constraint, together with the conditions that brought it into play, formed a cultural epicycle that militated for discrete, not graded, distinctions between signs. The altered niche, the advantageous structuring of which now depended on the enlarged vocabulary of signs in the protodiscourse, created a general selection for capacities that enhanced the production and comprehensibility of these signs; but at the same time the newly active ontological constraint made discrete production and processing an important part of those capacities. The epicycle acted as a control, biasing biocultural evolution and driving protodiscourse toward discreteness, and this feature would eventually come to be fundamental in the emergence of both language and music. Discreteness of timbre and onset and decay would mark off one uttered unit from another in the vowels, phonemes, and syllables of modern language, while discreteness of pitch would set off a cascade of new capacities, leading to the relative pitch perception, octave duplication, and scales of music today.

\section{Conclusion: Biological and Cultural Evolution: A Unified Field?}

Historical kinds are fundamental in both biology and culture, and these two perspectives converge on questions of the systems that characterize individual kinds. The view of the origination of historical kinds offered here depends on the coalescing of systems and the functional integration that emerges from it. The mechanisms of this integration come to control or regulate the kind, giving it its character of quasi-independence or autonomy, and this character is basic to the force of any system to define a historical kind. But the historical kind is determined not only by this coalescing and autonomy, but also by the persistence of its functional integration and thus its ability to form a lineage of descent. Our view is through and through a processual one, since the functional integration of components in our historical kinds, from cell type regulatory networks to hominin protodiscourse, is an ongoing process of interaction of the elements in any given kind.

We are struck by the deep-seated similarities of emergence and function extending across the historical kinds we have described. From molecular regulatory systems to cultural epicycles, there are constancies of pattern in the emergence, control, and stabilizing of these systems. These reveal that biological and cultural evolutions are foundationally connected to one another, but not in a way that is limited to structural analogies of natural and cultural selection. Instead they are linked in their patterns of emergence of systemic regulation and integration. In order to understand this the mechanisms of both biological and cultural systems must be understood at the deepest level. It is the functionalized content of these systems-the components that mesh, the manners in which they mesh, and the emergent functional qualities that take shape in the meshing- that must be attended to.

Finally, we think that these systemic constancies amount to something more than ontological accidents and point to the most general ways in which stable kinds can take shape within historical, evolving dynamics. The appearance of similar systems dynamics across vast ontological distances, from molecular biology to human culture, encourages us to suggest that the concept of historical kinds as we use it here can shed light on the unified field on which all systems evolution takes place.

\section{Acknowledgments}

The authors thank our colleagues, Drs. Richard Prum, Stephen Stearns, Mihaela Pavličev, James DiFrisco and Alan Love, for discussions as well as Professor John Dupré and an anonymous referee for advice on this paper. 


\section{Literature cited}

Arendt, D. 2003. "Evolution of Eyes and Photoreceptor Cell Types." Int. J. Dev. Biol. 47: 563- 571.

Arendt, D. 2008. "The Evolution of Cell Types in Animals: Emerging Principles From Molecular Studies.” Nature Reviews Genetics 9: 868-882.

Arendt, D., J. M. Musser, C. V. H. Baker, A. Bergman, C. Cepko, D. H. Erwin, M. Pavlicev, G. Schlosser, S. Widder, M. D. Laubichler and G. P. Wagner 2016. "The Origin and Evolution of Cell Types." Nat Rev Genet 17(12): 744-757.

Aunger, R. and V. Curtis. 2015. Gaining Control: How Human Behavior Evolved. Oxford: Oxford University Press.

Balari, S. and G. Lorenzo. 2013. Computational Phenotypes: Towards an Evolutionary Developmental Biolinguistics. Oxford: Oxford University Press.

Beecher, M. D. and J. M. Burt. 2004. "The Role of Social Interaction in Bird Song Learning." Current Directions in Psychological Science 13(6): 224-228.

Bell, C. 1992. Ritual Theory, Ritual Practice. New York: Oxford University Press.

Bertalanffy, L. V. 1969. General Systems Theory: Foundations, Development, Applications. New York: Braziller.

Bickerton, D. 1990. Language and Species. Chicago: University of Chicago Press.

Blackmore, S. 1999. The Meme Machine. Oxford: Oxford University Press.

Bloch, M. 2000. A Well-Disposed Social Anthropologist's Problem With Memes. In Darwinizing Culture: The Status of Memetics as a Science, edited by R. Aunger, 189-204. Oxford: UK: Oxford University Press.

Bloch, M. 2013. In and Out of Each Other's Bodies: Theory of Mind, Evolution, Truth, and the Nature of the Social. Boulder, CO: Paradigm.

Bowie, J. 2008. "Proto-Discourse and the Emergence of Compositionality." Interaction Studies 9: 1833.

Boyd, R. 1999. Homeostasis, Species, and Higher Taxa. Species: Nerw Interdiscuplinary Essays. A. B. Wilson. Cambridge, MIT Press: 141-185.

Boyd, R. and P. J. Richerson. 1985. Culture and the Evolutionary Process. Chicago: University of Chicago Press.

Boyd, R. and P. J. Richerson. 2005. The Origin and Evolution of Cultures. New York: Oxford University Press.

Brigandt, I. 2009. "Natural Kinds in Evolution and Systematics: Metaphysical and Epistemological Considerations." Acta Biotheoretica 57: 77-97.

Brunet, T., A. H. Fischer, P. R. Steinmetz, A. Lauri, P. Bertucci and D. Arendt. 2016. "The Evolutionary Origin of Bilaterian Smooth and Striated Myocytes." eLife 5.

Bueno, O., R.-L. Chen and M. B. Fagan, eds. 2018. Individuation, Process, and Scientific Practice. New York: Oxford University Press.

Burling, R. 2007. The Talking Ape: How Language Evolved. Oxford: Oxford University Press.

Buss, L. W. 1987. The Evolution of Individuality. New York: Columbia University Press.

Carruthers, P. and P. K. Smith. 1996. Theories of Theories of Mind. Cambridge, UK: Cambridge University Press. 
Cavalli-Sforza, L. L. and M. W. Feldman. 1981. Cultural Transmission and Evolution: A Quantitative Approach. Princeton, NJ: Princeton University Press.

D’Errico, F. and M. Vanhaeren. 2007. "Evolution or Revolution? New Evidence for the Origin of Symbolic Behaviour in and Out of Africa" In Rethinking the Human Revolution, edited by P. Mellars, K. Boyle, O. Bar-Yosef and C. Stringer, 275-286. Cambridge: The McDonald Institute.

Davidson, E. H. and D. H. Erwin. 2006. "Gene Regulatory Networks and the Evolution of Animal Body Plans.” Science 311: 796-800.

Dawkins, R. 1976. The Selfish Gene. New York: Oxford University Press.

Deacon, T. 1999. "Memes as Signs: The Trouble With Memes (And What to Do About It)." Semiotic Rev. of Books 10: 1-3.

DiFrisco, J., A. Love and G. P. Wagner. 2020. "Character-Identity Mechanisms: A Conceptual Model for Comparative-Mechanistic Biology” Biology \& Philosophy 35(4).

Donald, M. 1999. "Preconditions for the Evolution of Protolanguages." In The Descent of Mind: Psychological Perspectives on Hominid Evolution, edited by M. C. Corballis and S. E. G. Lea, 138-154. Oxford: Oxford University Press.

Dupré, J. 2012. Processes of Life: Essays in the Philosophy of Biology. Oxford: Oxford University Press.

Dupré, J. 2017. “The Metaphysics of Evolution.” Interface Focus 7.

Dupré, J. and D. J. Nicholson. 2018. “A Manifesto for a Processual Philosophy of Biology.” In Everything Flows: Towards a Processual Philosophy of Biology, edited by D. J. Nicholson and J. Dupré, 3-45. Oxford: Oxford University Press.

Emera, D. and G. P. Wagner. 2012. “Transformation of a Transposon Into a Derived Prolactin Promoter With Function During Human Pregnancy.” Proc Natl Acad Sci USA 109(28): 1124611251.

Fiete, I. R. and H. S. Seung. 2009. "Birdsong Learning.” In Encyclopedia of Neuroscience, edited by L. Squire, 227-239. New York: Elsevier.

Gamble, C. 1999. The Palaeolithic Societies of Europe. Cambridge, UK: Cambridge University Press.

Gardner, T. J., F. Naef and F. Nottebohm. 2005. "Freedom and Rules: The Acquisition and Reprogramming of a Bird's Learned Song." Science 308: 1046-1049.

Gehring, W. 1998. Master Control Genes in Development and Evolution: The Homeobox Story. New Haven, CT: Yale University Press.

Ghiselin, M. T. 1974. "A Radical Solution to the Species Problem.” Syst Zool 23: 536-544.

Ghiselin, M. T. 1997. Metaphysics and the Origin of Species. New York: State University of New York Press.

Gilbert, S. F., J. Sapp and A. I. Tauber. 2012. "A Symbiotic View of Life: We Have Never Been Individuals." Quarterly Review of Biology 87(4): 325-341.

Godfrey-Smith, P. 2009. Darwinian Populations and Natural Selection. Oxford: UK, Oxford University Press.

Godfrey-Smith, P. 2014. Philosophy of Biology. Princeton, NJ: Princeton University Press.

Gould, S. J. 1982. "Introduction.” In Genetics and the Origin of Species by T. Dobzhansky, xvii-xli. New York: Columbia University Press.

Grauer, D. and W.-H. Li. 2000. Fundamentals of Molecular Evolution. Sunderland, MA: Sinauer Assoc. 
Griesemer, J. 2000. "Development, Culture and the Units of Inheritance.” Phil. Science 67: S348S368.

Griesemer, J. 2018. "Individuation of Developmental Systems.” In Individuation, Process, and Scientific Practices, edited by O. Bueno, R.-L. Chen and M. B. Fagan, 137- 164. Oxford: Oxford University Press.

Griffiths, P. E. 1999. "Squaring the Circle: Natural Kinds With Historical Essences.” In Species: New Interdisciplinary Essays. edited by R. A. Wilson, 209-228. Cambridge, MIT Press.

Haladjian, H. H. and C. Montemayor. 2015. "On the Evolution of Conscious Attention.” Psychon Bull Rev 22(3): 595-613.

Hartl, D. L. and A. G. Clark. 1989. Principles of Population Genetics. Sunderland, MA: Sinauer Associates.

Hennig, W. 1966. Phylogenetic Systematics. Urbana, IL: University of Illinois Press.

Hobert, O. 2011. "Regulation of Terminal Differentiation Programs in the Nervous System." Annu Rev Cell Dev Biol 27: 681-696.

Hull, D. L. 1978. “A Matter of Individuality.” Philosophy of Science 45: 335-360.

Hull, D. L. 1980. "Individuality and Selection.” Annu. Rev. Ecol. Syst. 11: 311-332.

Kauffman, S. A. 1993. The Origins of Order: Self-Organization and Selection in Evolution. New York: Oxford University Press.

Klein, R. G. 2009. The Human Career: Human Biological and Cultural Origins. Chicago: IL, University of Chicago Press.

Knudsen, E. I. 2007. "Fundamental Components of Attention.” Annu Rev Neurosci 30: 57-78.

Kondrashov, F. A., I. B. Rogozin, Y. I. Wolf and E. V. Koonin. 2002. "Selection in the Evolution of Gene Duplications." Genome Biology 3: REASEARCH0008.

Kripke, S. 1980. Naming and Necessity. Cambridge, MA: Harvard University Press.

Laland, K. N., J. Odling-Smee and S. Myles. 2010. "How Culture Shaped the Human Genome: Bringing Genetics and the Human Sciences Together." Nature Review Genetics 11: 137-148.

Laland, K. N., T. Uller, M. W. Feldman, K. Sterelny, G. B. Muller, A. Moczek, E. Jablonka and J. Odling-Smee. 2015. "The Extended Evolutionary Synthesis: Its Structure, Assumptions and Predictions.” Proc Biol Sci 282(1813): 20151019.

Laubichler, M. D. and J. Renn. 2015. "Extended Evolution: A Conceptual Framework for Integrating Regulatory Networks and Niche Construction.” J Exp Zool B Mol Dev Evol 324(7): 565- 577.

Lee, S., B. Lee, K. Joshi, S. L. Pfaff, J. W. Lee and S. K. Lee. 2008. "A Regulatory Network to Segregate the Identity of Neuronal Subtypes.” Dev Cell 14(6): 877-889.

Li, W.-H. 1985. "Accelerated Evolution Following Gene Duplication and Its Implication for the Neutralist-Selectionist Controversy." In Population Genetics and Molecular Evolution. edited by T. Ohta and K. Aoki, 333-352. Tokyo, Japan: Sci. Soc. Press.

Love, A. C. 2018. "Individuation, Individuality, and Experimental Practice in Developmental Biology.” In Individuation, Process, and Scientific Practices, edited by O. Bueno, R.-L. Chen and M. B. Fagan, 165-191. Oxford: Oxford University Press.

Lynch, M. 2007. The Origins of Genome Architecture. Sunderland, MA: Sinauer Associates.

Lynch, V. J., M. C. Nnamani, A. Kapusta, K. Brayer, S. L. Plaza, E. C. Mazur, D. Emera, S. Z. Sheikh, F. Grutzner, S. Bauersachs, A. Graf, S. L. Young, J. D. Lieb, F. J. DeMayo, C. Feschotte and G. P. Wagner. 2015. "Ancient Transposable Elements Transformed the Uterine Regulatory 
Landscape and Transcriptome During the Evolution of Mammalian Pregnancy." Cell Rep 10(4): $551-561$.

Marler, P. and H. Slabberkoorn. 2004. Nature's Music: The Science of Birdsong. San Diego, CA: Elsevier.

Mayr, E. 1963. Animal Species and Evolution. Cambridge, MA: Harvard University Press.

McBrearty, S. and A. S. Brooks. 2000. "The Revolution That Wasn't: A New Interpretation of the Origin of Modern Human Behavior.” Journal of Human Evolution 39: 453-563.

Mesoudi, A. 2011. Cultural Evolution: How Darwinian Theory Can Explain Human Culture E Synthesize the Social Sciences. Chicago University of Chicago Press.

Meyer, A. and M. Schartl. 1999. "Gene and Genome Duplications in Vertebrates: The One-to- Four (-to-Eight in Fish) Rule and the Evolution of Novel Gene Functions." Curr Opin Cell Biol 11: 699-704.

Michod, R. E. and M. D. Herron. 2006. "Cooperation and Conflict During Evolutionary Transitions in Individuality." J Evol Biol 19(5): 1406-1409; Discussion 1426-1436.

Millikan, R. G. 1999. "Historical Kinds and the 'Special Sciences'.” Philosophical Studies 95: 45- 65.

Millikan, R. G. 2017. Beyond Concepts: Unicepts, Language, and Natural Information. Chicago: Oxford University Press.

Nottebohm, F. 2005. “The Neural Basis of Birdsong.” PLoS Biology 3(5): 0759-0761.

Odling-Smee, F. J., K. N. Laland and M. W. Feldman. 2003. Niche Construction: The Neglected Process in Evolution. Princeton, NJ: Princeton University Press.

Pemberton, J. 2018. “Individuating Processes.” In Individuation, Process, and Scientific Practices, edited by O Bueno, R.-L. Chen and M. B. Fagan, 39-62. Oxford: Oxford University Press.

Pigliucci, M. 2007. “Do We Need an Extended Evolutionary Synthesis?” Evolution 61(12): 27432749.

Pigliucci, M. and G. B. Müller, eds. 2010. Evolution: The Extended Synthesis. Cambridge, MA: MIT Press.

Pope, M. and M. Roberts. 2005. "Observations on the Relationship Between Palaeolithic Individuals and Artefact Scatters at the Pleistocene Site of Boxgrove, UK". In The Hominid Individual in Context: Archaeological Investigations of Lower and Middle Palaeolithic Landscapes, Locales, and Artefacts, edited by C. Gamble and M. Porr, 81-97. New York: Routledge.

Putnam, H. 1975. Mind, Language and Reality: Philosophical Papers. Cambridge: Cambridge University Press.

Renn, J. 2020. The Evolution of Knowledge: Rethinking Science for the Anthropocene. Princeton: Princeton University Press.

Richerson, P. J. and R. Boyd. 2005. Not by Genes Alone: How Culture Transformed Human Evolution. Chicago and London: University of Chicago Press.

Richerson, P. J., R. Boyd and R. L. Bettinger. 2009. "Cultural Innovations and Demographic Change." Human Biology 81: 211-235.

Runciman, W. G. 2009. The Theory of Cultural and Social Selection. Cambridge Cambridge University Press.

Shennan, S. 2001. "Demography and Cultural Innovation: A Model and Its Implications for the Emergence of Modern Human Culture.” Cambridge Archaeological Journal 11: 5-16. 
Slagsvold, T. and K. L. Wiebe. 2011. "Social Learning in Birds and Its Role in Shaping a Foraging Niche." Philosophical Transactions of the Royal Society B 366: 969-977.

Smith, C. L., F. Varoqueaux, M. Kittelmann, R. N. Azzam, B. Cooper, C. A. Winters, M. Eitel, D. Fasshauer and T. S. Reese. 2014. "Novel Cell Types, Neurosecretory Cells, and Body Plan of the Early-Diverging Metazoan Trichoplax Adhaerens.” Curr Biol 24(14): 1565-1572.

Sperber, D. 1996. Explaining Culture: A Naturalistic Approach. Oxford: UK, Cambridge, MA: Blackwell.

Sterelny, K. 2012. The Evolved Apprentice: How Evolution Made Humans Unique. Cambridge, MA, MIT Press.

Taleb, N. N. 2012. Antifragile: Things That Gain From Disorder. New York: Random House.

Tambiah, S. J. 1979. "A Performative Approach to Ritual." Proceedings of the British Academy 65: 113169.

Tchernikovski, O. and G. Marcus. 2014. "Learning Beyond Imitation: Mechanisms of Adaptive Vocal Development in Songbirds and Human Infants." Current Opinion in Neurobiology 28C: 42-47.

Templeton, A. 1989. “The Meaning of Species and Speciation: A Genetic Perspective." In Speciation and Its Consequences, edited by D. Otte and J. A. Endler, 3-27. Sunderland, MA: Sinauer.

Tomasello, M. 1999. The Cultural Origins of Human Cognition. Cambridge, MA: Harvard University Press.

Tomasello, M. 2008. Origins of Human Communication. Cambridge, MA, MIT Press.

Tomasello, M., M. Carpenter, J. Call, T. Behne and H. Moll. 2005. "Understanding and Sharing Intentions: The Origins of Cultural Cognition.” Behav Brain Sci 28(5): 675-691; Discussion: 691735 .

Tomlinson, G. 2015. A Million Years of Music: The Emergence of Human Modernity. New York: Zone Books.

Tomlinson, G. 2018. Culture and the Course of Human Evolution. Chicago and London: University of Chicago Press.

Valentine, J. W., A. G. Collins and C. P. Meyer. 1994. "Morphological Complexity Increase in Metazoans." Paleobiology 20: 131-142.

Van De Peer, Y., S. Maere and A. Meyer. 2009. “The Evolutionary Significance of Ancient Genome Duplications." Nat Rev Genet 10(10): 725-732.

Vanhaeren, M. and F. D’Errico. 2006. "Aurignacian Ethno-Linguistic Geography of Europe Revealed by Personal Ornaments.” J. Archeological Sci. 33: 1105-1128.

Vickaryous, M. K. and B. K. Hall. 2006. "Human Cell Type Diversity, Evolution, Development, and Classification With Special Reference to Cells Derived From the Neural Crest." Biol Rev Camb Philos Soc 81(3): 425-455.

Virchow, R. 1860. Celluar Pathology. London, John Churchill.

Wagner, G. P. 2007. “The Developmental Genetics of Homology.” Nature Rev. Genetics 8: 473- 479.

Wagner, G. P. 2014. Homology, Genes and Evolutionary Innovation. Princeton, NJ: Princeton University Press.

White, R. 2007. "Systems of Personal Ornamentation in the Early Upper Palaeoithic: Methodological Challenges and New Observations." In Rethinking the Human Revolution, edited by P. Mellars, K. Boyle, O. Bar-Yosef and C. Stringer. Cambridge: The McDonald Institute: 287-302. 
Wynn, T. 2002. "Archaeology and Cognitive Evolution.” Behav Brain Sci 25(3): 389-402; and Discussion: 403-338.

Zhang, Q. J. Pi, C. G. Woods, and M. E. Andersen. 2010. "A Systems Biology Perspective on Nrf2Mediated Antioxidant Response.” Toxicol Appl Pharmacol 244(1): 84-97.

(C) 2022 Author(s)

This is an open-access article distributed under the terms of the Creative Commons Attribution 4.0 International license, which permits anyone to download, copy, distribute, display, or adapt the text without asking for permission, provided that the creator(s) are given full credit.

ISSN 2475-3025 